\title{
ClinicAl CONTRIBUtions to CONSCIOUSNESS STUDIES
}

\author{
George A. Mashour*, Ashley Turner \\ University of Michigan Medical School \\ Ann Arbor, MI, USA \\ Received August 20, 2009; accepted October 10, 2009
}

\begin{abstract}
Consciousness is a multidisciplinary subject of inquiry. The extent of clinical contributions to the field of consciousness studies has yet to be investigated. The goal of this study was to assess the degree of clinically related articles in the literature of consciousness studies through a systematic evaluation. Three journals systematically identified (Consciousness and Cognition, Journal of Consciousness Studies, and Anthropology of Consciousness) were reviewed from the first issue through December 2008. All original articles related to anesthesiology, general clinical medicine, neurology, neurosurgery, and psychiatry were identified. Of the 1,805 articles reviewed for the three journals, a total of 149 clinically relevant articles were identified; this represented an average contribution of $8 \%$ to the total articles. Psychiatry was the discipline most consistently represented in the three journals; neurosurgery was the least represented. There is a relative paucity of clinical articles in the literature of consciousness studies. Clinical perspectives may thus be underrepresented in the field.
\end{abstract}

Key words: Consciousness; Consciousness studies; Meta-analysis

\section{INTRODUCTION}

The study of consciousness is a richly interdisciplinary endeavor, involving philosophy, psychology, cognitive science, neuroscience, physics, and numerous other fields. Clinical disciplines such as neurology, psychiatry, neurosurgery, and anesthesiology all deal with the disturbance or disruption of consciousness. As such, studies and reports related to these disciplines may potentially enrich the discourse of consciousness studies. For example, anesthesiologists regularly initiate a deep state of reversible unconsciousness, providing a unique opportunity for understanding the molecular and neurophysiologic mechanisms of consciousness.

Similarly, the hallucinatory experiences of neuropsychiatric patients or cognitive deficits of neurosurgical patients may yield insight into the neural substrates of consciousness through clinicopathologic correlation. Thus, the clinical perspective is vital to the progress of consciousness studies, but the extent of clinical contributions to the field has yet to be investigated. The goal of this study was therefore to assess the degree of clinically related articles in the literature of consciousness studies through a systematic evaluation.

\section{METHODS}

Journals devoted primarily to the publication of original articles on consciousness studies were identified systematically. A journal search on PubMed using the term "consciousness" yielded only Consciousness and Cognition. An internet search (Google) using the terms "consciousness journal" and "consciousness journals" further yielded Journal of Consciousness Studies, Psyche, Anthropology of Consciousness, International Journal of Machine Consciousness, and Science and Consciousness Review. Psyche was excluded because it did not have a continuous publication history, with no articles published in Volumes 2, 6, 7 or the year 2008. International Journal of Machine Consciousness was excluded, as the first volume was not scheduled to appear until 2009. Science and Consciousness Review was excluded because it publishes summaries rather than original articles. Thus, the journals Consciousness and Cognition (C\&C), Journal of Consciousness Studies (JCS), and Anthropology of Consciousness (AoC) were deemed appropriate for analysis.

All volumes of C\&C (1992- ), JCS (1994- ), and AoC (1990- ) were reviewed from the first issue through December, 2008. All titles and abstracts were evaluated

*Correspondence to: George Mashour,email: gmashour@med.umich.edu 
for elements related to anesthesiology, neurology, neurosurgery, psychiatry (and related disciplines such as psychoanalysis) or general clinical medicine. If such elements appeared to be central, the article was deemed to be clinical. The text of the articles themselves was reviewed if ambiguity existed.
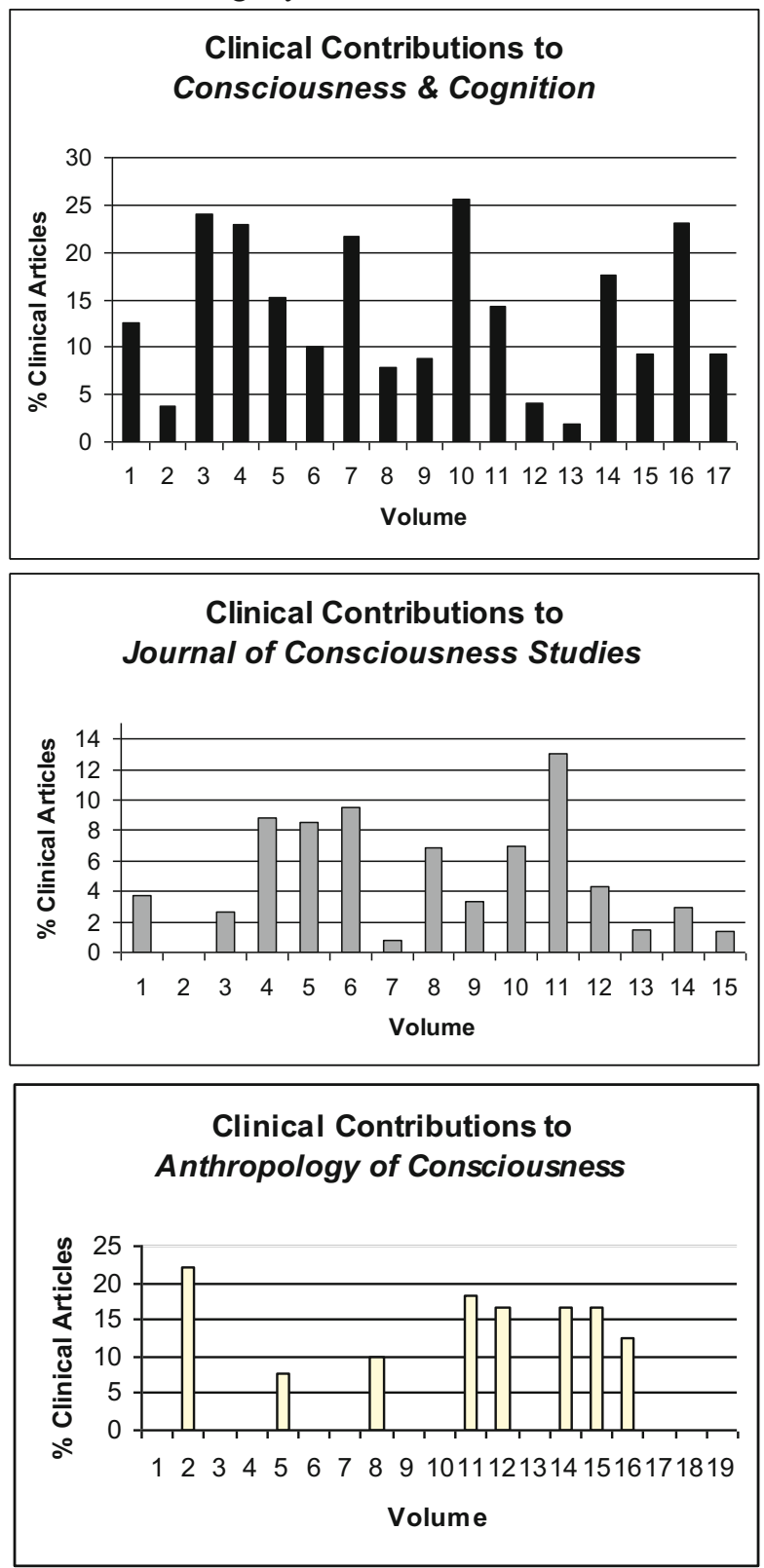

Figure 1. Clinical contributions as a percentage of total original articles to Consciousness and Cognition (a), Journal of Consciousness Studies (b), and Anthropology of Consciousness (c). Every journal from the first issue through December, 2008 was reviewed.

Editorial introductions, book reviews, conference announcements or reviews, calls for articles, interviews, obituaries, commentaries and replies were all excluded.
"Commentary" was determined by an explicit statement in the title of the article, or based on the categorization of the journal. The percentage of clinically related articles in the target journals was assessed and compared; the representation of fields comprising the clinical articles was also assessed.

\section{RESULTS}

$\mathrm{C} \& \mathrm{C}$ had the most clinical articles in absolute numbers (96 clinical/746 total), as well as the highest percentage of clinical articles (13\%) (Figure 1a). JCS had 43 clinical/ 888 total articles, representing $5 \%$ of total articles in that journal (Figure 1b). AoC had only 10 clinical/171 total articles, representing $6 \%$ of total articles in that journal (Figure 1c). Please see the Appendix for full listing of clinical articles from the three journals analyzed.

Psychiatry and related disciplines had the best representation in the three journals; neurosurgery had the worst (Figure 2).

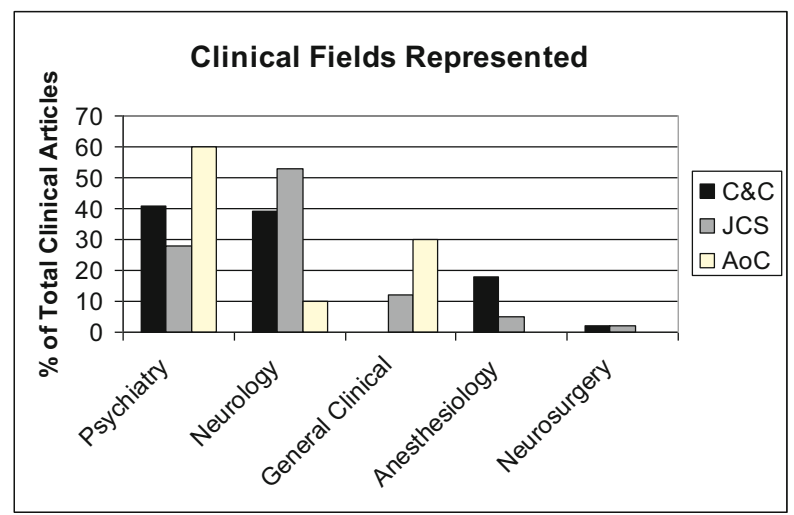

Figure 2. Representation of the clinical disciplines analyzed. Values were normalized as percentages for comparison.

\section{DISCUSSION}

This is the first study to evaluate the degree of clinically related contributions to the literature of consciousness studies. Consciousness and Cognition had the largest percentage of clinically related articles, as well as the largest absolute number. This may be attributable to the fact that it is the only journal focused on consciousness that is indexed in PubMed. Of the clinical fields, psychiatry and related disciplines were most consistently represented among the three journals analyzed.

It is difficult to make hard conclusions or recommendations based on these findings, as the degree to which clinical disciplines should contribute to the literature of consciousness is unclear. That being said, the pathology observed in the clinical setting may provide significant insight to the study of consciousness - the fact that less than $10 \%$ of articles in 
$\mathrm{C} \& \mathrm{C}$, JCS and AoC are clinically relevant suggests that such insights may be underrepresented. There are several possible reasons to account for this. First, clinicians or clinical researchers may not perceive their work under the rubric of "consciousness studies" and may thus submit their research to primary journals in their own field. Second, the paucity of clinically related articles may reflect a lack of interest or knowledge of clinical topics by researchers primarily interested in consciousness. Third, these data may suggest that the lack of academic legitimacy of consciousness studies characteristic of the 20th century still persists in the clinical realm. Although not assessed in the current study, it would be of further interest to investigate how many authors of these clinical studies were actually clinicians.

In terms of the fields represented, it was surprising to see the small contribution of anesthesiology to the total clinical articles. Unlike psychiatrists, neurologists, or neurosurgeons, the primary clinical activity of anesthesiologists is the manipulation of normal human consciousness-it is thus unclear why there has not been better representation in the field of consciousness studies proper. Perhaps the recent high-profile discussion of consciousness and anesthesia in the literature (Alkire, Hudetz, Tononi, 2008) will stimulate further interest and academic activity.

There are several limitations to the current study. First, the determination of clinical relevance can be subjective. Certain subjects are unambiguously clinical (such as blindsight or schizophrenia for example), whereas others require interpretation. Although some choices in the present study could be subject to discussion, it is likely that the primary results would be unchanged. Another limitation relates to the category of commentaries. Some articles or journal classifications clearly denote an article as a commentary, while others do not. In general, if the target article is theoretical, the commentary may be just as "original" in nature and should therefore be included as such. To avoid ambiguity, the decision was made to exclude as commentaries only articles that were explicitly labeled as such. There may thus be instances in which incorrect inclusion or exclusion would alter the outcome. Again, we do not think that such instances would significantly alter the primary results. Finally, this study addresses only the presence, rather than the overall impact, of a clinical contribution.

We are still in the early methodological stages of consciousness studies. The present data indicate that clinical fields directly related to the investigation of consciousness may not yet be fully integrated Further work on the role of the clinical sciences in the study of consciousness is warranted.
Appendix: Clinical articles identified in AoC (1990 through December, 2008), C\&C (1992 through December, 2008), and JCS (1994 through December, 2008), listed alphabetically for each journal.

\section{Anthropology of Consciousness}

1. Budden A: Pathologizing Possession: An Essay on Mind, Self, and Experience in Dissociation. Anthropology of Consciousness 2003; 14: 27-59

2. Calabrese JD: The Supreme Court versus Peyote: Consciousness Alteration, Cultural Psychiatry and the Dilemma of Contemporary Subcultures. Anthropology of Consciousness 2001; 12: 4-18

3. Jervis LL: Finding Order in David's Disorder. Anthropology of Consciousness 1997; 8: 97-105

4. Lynch D: Patient Preparation and Perceived Outcomes of Spiritist Healing in Brazil. Anthropology of Consciousness 2004; 15: 10-41

5. Lynn CD: Adaptive and Maladaptive Dissociation: An Epidemiological and Anthropological Comparison and Proposition for an Expanded Dissociation Model. Anthropology of Consciousness 2005; 16: 16-49

6. Ostlund SK: Doctors, Nurses, \& Patients: Who Has Control Over Death And Dying? Anthropology of Consciousness 2000; 11: 78-89

7. Peters LG: Rites of Passage and the Borderline Syndrome: Perspectives in Transpersonal Anthropology. Anthropology of Consciousness 1994; 5: $1-15$

8. Saxton K, Govertsen E: Field Play: The Normalization of an Alternate Cognizance in Seriously Ill Children. Anthropology of Consciousness 2000; 11: 14-23

9. Winkelman M: Therapeutic Effects of Hallucinogens. Anthropology of Consciousness 1991; 2: 15-19

10. Wright PA: Rhythmic Drumming in Contemporary Shamanism and Its Relationship to Auditory Driving and Risk of Seizure Precipitation in Epileptics. Anthropology of Consciousness 1991; 2: 7-14

\section{Consciousness and Cognition}

11. Alkire MT: The Power of Observation. Consciousness and Cognition 2001; 10: 236-240

12. Alkire MT, Haier RJ, Fallon JH: Toward a Unified Theory of Narcosis: Brain Imaging Evidence for a Thalamocortical Switch as the Neurophysiologic Basis of Anesthetic-Induced Unconsciousness. Consciousness and Cognition 2000; 9: 370-386

13. Hobson JA: Sleep and dream suppression following a lateral medullary infarct: A first-person account. Consciousness and Cognition 2002; 11: 377-390

14. Alpert JL: Trauma, Dissociation, and Clinical Study as a Responsible Beginning. Consciousness and Cognition 1995; 4: 125-129

15. Andrade J: Investigations of Hypesthesia: Using Anesthetics to Explore Relationships between 
Consciousness, Learning, and Memory. Consciousness and Cognition 1996; 5: 562-580

16. Andrade J, Munglani R, Jones JG, Baddeley AD: Cognitive Performance during Anesthesia. Consciousness and Cognition 1994; 3: 148-165

17. Asai T, Sugimori E, Tanno Y: Schizotypal personality traits and prediction of one's own movements in motor control: What causes an abnormal sense of agency? Consciousness and Cognition 2008; 17: 1131-1142

18. Baars BJ: The Brain Basis of a "Consciousness Monitor": Scientific and Medical Significance. Consciousness and Cognition 2001; 10: 159-164

19. Baars BJ, Banks WP: Introduction: The evidence for anosognosia. Consciousness and Cognition 1992; 1: $148-151$

20. Baars BJ, McGovern K: Steps toward Healing: False Memories and Traumagenic Amnesia May Coexist in Vulnerable Populations. Consciousness and Cognition 1995; 4: 68-74

21. Bacon E, Danion J-M, Kauffmann-Muller F, Bruant A: Consciousness in Schizophrenia: A Metacognitive Approach to Semantic Memory. Consciousness and Cognition 2001; 10: 473-484

22. Ballard CG, Court JA, Piggott M, Johnson M, O'Brien J, McKeith I, Holmes C, Lantos P, Jaros E, Perry R, Perry E: Disturbances of consciousness in dementia with Lewy bodies associated with alteration in nicotinic receptor binding in the temporal cortex. Consciousness and Cognition 2002; 11: 461-474

23. Banks WP: Korsakoff and Amnesia. Consciousness and Cognition 1996; 5: 22-26

24. Barnett KJ, Kirk IJ, Corballis MC: Bilateral disadvantage: Lack of interhemispheric cooperation in schizophrenia. Consciousness and Cognition 2007; 16: 436-444

25. Barnett KJ, Newell FN: Synaesthesia is associated with enhanced, self-rated visual imagery. Consciousness and Cognition 2008; 17: 1032-1039

26. Becchio C, Bertone C: The ontology of neglect. Consciousness and Cognition 2005; 14: 483-494

27. Behrmann M, Meegan DV: Visuomotor Processing in Unilateral Neglect. Consciousness and Cognition 1998; 7: 381-409

28. Bisiach E, Neppi-Mòdona M, Genero R, Pepi R: Anisometry of Space Representation in Unilateral Neglect: Empirical Test of a Former Hypothesis. Consciousness and Cognition 1999; 8: 577-584

29. Bisiach E, Ricci R, Mòdona MN: Visual Awareness and Anisometry of Space Representation in Unilateral Neglect: A Panoramic Investigation by Means of a Line Extension Task. Consciousness and Cognition 1998; 7 : 327-355

30. Blair RJR: Responding to the emotions of others: Dissociating forms of empathy through the study of typical and psychiatric populations. Consciousness and Cognition 2005; 14: 698-718

31. Bogen JE: On the Neurophysiology of Consciousness: 1. An Overview. Consciousness and Cognition 1995; 4: 52-62

32. Bogen JE: On the Neurophysiology of Consciousness: Part II. Constraining the Semantic Problem. Consciousness and Cognition 1995; 4: 137-158

33. Bonebakker AE, Jelicic M, Passchier J, Bonke B: Memory during General Anesthesia: Practical and Methodological Aspects. Consciousness and Cognition 1996; 5: 542-561

34. Bowler DM, Gardiner JM, Gaigg SB: Factors affecting conscious awareness in the recollective experience of adults with Asperger's syndrome. Consciousness and Cognition 2007; 16: 124-143

35. Brennen T, Dybdahl R, Kapidzic A: Trauma-related and neutral false memories in war-induced Posttraumatic Stress Disorder. Consciousness and Cognition 2007; 16: 877-885

36. Cahill C, Al-Eithan M, Frith CD: Conscious and Unconscious Rule-Induction: A Neuropsychological Case Study. Consciousness and Cognition 1993; 2: 210224

37. Cariani P: Anesthesia, Neural Information Processing, and Conscious Awareness. Consciousness and Cognition 2000; 9: 387-395

38. Caseley-Rondi G, Merikle PM, Bowers KS: Unconscious Cognition in the Context of General Anesthesia. Consciousness and Cognition 1994; 3: 166195

39. Cermolacce M, Naudin J, Parnas J: The "minimal self" in psychopathology: Re-examining the selfdisorders in the schizophrenia spectrum. Consciousness and Cognition 2007; 16: 703-714

40. Cheyne JA, Girard TA: Paranoid delusions and threatening hallucinations: A prospective study of sleep paralysis experiences. Consciousness and Cognition 2007; 16: 959-974

41. Danion J-M, Cuervo C, Piolino P, Huron C, Riutort M, Peretti CS, Eustache F: Conscious recollection in autobiographical memory: An investigation in schizophrenia. Consciousness and Cognition 2005; 14: 535-547

42. Danziger S, Fendrich R, Rafal RD: Inhibitory Tagging of Locations in the Blind Field of Hemianopic Patients. Consciousness and Cognition 1997; 6: 291307

43. de Vignemont F, Zalla T, Posada A, Louvegnez A, Koenig O, Georgieff N, Franck N: Mental rotation in schizophrenia. Consciousness and Cognition 2006; 15 : 295-309

44. Deeprose C, Andrade J: Is priming during anesthesia unconscious? Consciousness and Cognition 2006; 15: 1-23 
45. Deouell LY: Pre-requisites for conscious awareness: Clues from electrophysiological and behavioral studies of unilateral neglect patients. Consciousness and Cognition 2002; 11: 546-567

46. Dijkerman HC, Milner AD, Carey DP: Grasping Spatial Relationships: Failure to Demonstrate Allocentric Visual Coding in a Patient with Visual Form Agnosia. Consciousness and Cognition 1998; 7: 424437

47. Enriquez P, Bernabeu E: Hemispheric laterality and dissociative tendencies: Differences in emotional processing in a dichotic listening task. Consciousness and Cognition 2008; 17: 267-275

48. Feinberg TE, Keenan JP: Where in the brain is the self? Consciousness and Cognition 2005; 14: 661-678

49. Forrest KA: Toward an Etiology of Dissociative Identity Disorder: A Neurodevelopmental Approach. Consciousness and Cognition 2001; 10: 259-293

50. Fosse R: REM mentation in narcoleptics and normals: an empirical test of two neurocognitive theories. Consciousness and Cognition 2000; 9: 488509

51. Frith C: The self in action: Lessons from delusions of control. Consciousness and Cognition 2005; 14: 752770

52. Frith $U$, de Vignemont F: Egocentrism, allocentrism, and Asperger syndrome. Consciousness and Cognition 2005; 14: 719-738

53. Galin D: Theoretical reflections on awareness, monitoring, and self in relation to anosognosia. Consciousness and Cognition 1992; 1: 152-162

54. Gambini O, Barbieri V, Scarone S: Theory of Mind in schizophrenia: First person vs third person perspective. Consciousness and Cognition 2004; 13: 3946

55. Geraerts E, Kozaric-Kovacic D, Merckelbach H, Peraica T, Jelicic M, Candel I: Traumatic memories of war veterans: Not so special after all. Consciousness and Cognition 2007; 16: 170-177

56. Geraerts E, Smeets E, Jelicic M, van Heerden J, Merckelbach H: Fantasy proneness, but not selfreported trauma is related to DRM performance of women reporting recovered memories of childhood sexual abuse. Consciousness and Cognition 2005; 14: $602-612$

57. Glazebrook CM, Elliott D, Lyons J: Temporal judgements of internal and external events in persons with and without autism. Consciousness and Cognition 2008; 17: 203-209
58. Guterman Y: A neural plasticity perspective on the schizophrenic condition. Consciousness and Cognition 2007; 16: 400-420

59. Halligan PW, Marshall JC: Neglect of Awareness. Consciousness and Cognition 1998; 7: 356-380

60. Hameroff S: Anesthesia: The "Other Side" of Consciousness. Consciousness and Cognition 2001; 10: 217-229

61. Hembrooke H, Ceci SJ: Traumatic Memories: Do We Need to Invoke Special Mechanisms? Consciousness and Cognition 1995; 4: 75-82

62. Heywood CA, Kentridge RW, Cowey A: Cortical Color Blindness is Not "Blindsight for Color". Consciousness and Cognition 1998; 7: 410-423

63. Huntjens RJC, Postma A, Woertman L, van der Hart $\mathrm{O}$, Peters ML: Procedural memory in dissociative identity disorder: When can inter-identity amnesia be truly established? Consciousness and Cognition 2005; 14: 377-389

64. John ER, Prichep LS, Kox W, Valdés-Sosa P, Bosch-Bayard J, Aubert E, Tom M, diMichele F, Gugino LD: Invariant Reversible QEEG Effects of Anesthetics. Consciousness and Cognition 2001; 10: 165-183

65. Kentridge RW: Why Do Stationary Visual Transients Apparently Fail to Elicit Phenomenal Vision after Unilateral Destruction of Primary Visual Cortex? Consciousness and Cognition 2001; 10: 588-590

66. Kihlstrom JF: The Trauma-Memory Argument. Consciousness and Cognition 1995; 4: 63-67

67. Kircher TTJ, Leube DT: Self-consciousness, selfagency, and schizophrenia. Consciousness and Cognition 2003; 12: 656-669

68. Korsakoff SS: Medico-Psychological Study of a Memory Disorder. Consciousness and Cognition 1996; 5: $2-21$

69. Laureys S, Perrin F, Brédart S: Self-consciousness in non-communicative patients. Consciousness and Cognition 2007; 16: 722-741

70. Lysaker PH, Tsai J, Maulucci AM, Stanghellini G: Narrative accounts of illness in schizophrenia: Association of different forms of awareness with neurocognition and social function over time. Consciousness and Cognition 2008; 17: 1143-1151

71. Mashour GA, LaRock E: Inverse zombies, anesthesia awareness, and the hard problem of unconsciousness. Consciousness and Cognition 2008; 17: 1163-1168

72. McKay R, Cipolotti L: Attributional style in a case of Cotard delusion. Consciousness and Cognition 2007; 16: 349-359

73. McKay R, Langdon R, Coltheart M: Models of misbelief: Integrating motivational and deficit theories of delusions. Consciousness and Cognition 2007; 16: 932-941 
74. Merikle PM, Daneman M: Memory for Unconsciously Perceived Events: Evidence from Anesthetized Patients. Consciousness and Cognition 1996; 5: 525-541

75. Natsoulas T: A Rediscovery of Sigmund Freud. Consciousness and Cognition 1995; 4: 300-322

76. Neumann A, Blairy S, Lecompte D, Philippot P: Specificity deficit in the recollection of emotional memories in schizophrenia. Consciousness and Cognition 2007; 16: 469-484

77. Pacherie E, Green M, Bayne T: Phenomenology and delusions: Who put the [']alien' in alien control? Consciousness and Cognition 2006; 15: 566-577

78. Persaud N, Cowey A: Blindsight is unlike normal conscious vision: Evidence from an exclusion task. Consciousness and Cognition 2008; 17: 1050-1055

79. Persaud N, Lau H: Direct assessment of qualia in a blindsight participant. Consciousness and Cognition 2008; 17: 1046-1049

80. Peters ML, Uyterlinde SA, Consemulder J, van der Hart O: Apparent Amnesia on Experimental Memory Tests in Dissociative Identity Disorder: An Exploratory Study. Consciousness and Cognition 1998; 7: 27-41

81. Petitmengin C, Navarro V, Le Van Quyen M: Anticipating seizure: Pre-reflective experience at the center of neuro-phenomenology. Consciousness and Cognition 2007; 16: 746-764

82. Plourde G: Identifying the Neural Correlates of Consciousness: Strategies with General Anesthetics. Consciousness and Cognition 2001; 10: 241-244

83. Pockett S: Anesthesia and the Electrophysiology of Auditory Consciousness. Consciousness and Cognition 1999; 8: 45-61

84. Price EH: A critical review of congenital phantom limb cases and a developmental theory for the basis of body image. Consciousness and Cognition 2006; 15: 310-322

85. Proust J: Self Model and Schizophrenia. Consciousness and Cognition 1999; 8: 378-384

86. Ramachandran VS: Anosognosia in Parietal Lobe Syndrome. Consciousness and Cognition 1995; 4: 22-51 87. Rossetti Y: Implicit Short-Lived Motor Representations of Space in Brain Damaged and Healthy Subjects. Consciousness and Cognition 1998; 7: 520558

88. Schwender D, Madler C, Klasing S, Peter K, Pöppel E: Anesthetic Control of $40-\mathrm{Hz}$ Brain Activity and Implicit Memory. Consciousness and Cognition 1994; 3: 129-147

89. Shevrin H, Ghannam JH, Libet B: A Neural Correlate of Consciousness Related to Repression. Consciousness and Cognition 2002; 11: 334-341

90. Shevrin H, Williams WJ, Marshall RE, Hertel RK, Bond JA, Brakel LA: Event-related potential indicators of the dynamic unconscious. Consciousness and Cognition 1992; 1: 340-366
91. Smilek D, Callejas A, Dixon MJ, Merikle PM: Ovals of time: Time-space associations in synaesthesia. Consciousness and Cognition 2007; 16: 507-519

92. Solomonova E, Nielsen T, Stenstrom P, Simard V, Frantova E, Donderi D: Sensed presence as a correlate of sleep paralysis distress, social anxiety and waking state social imagery. Consciousness and Cognition 2008; 17: 49-63

93. Sonntag P, Gokalsing E, Olivier C, Robert P, Burglen F, Kauffmann-Muller F, Huron C, Salame P, Danion J-M: Impaired strategic regulation of contents of conscious awareness in schizophrenia. Consciousness and Cognition 2003; 12: 190-200

94. Stoerig P, Barth E: Low-Level Phenomenal Vision Despite Unilateral Destruction of Primary Visual Cortex. Consciousness and Cognition 2001; 10: 574587

95. Tapp TD: Blindsight in Hindsight. Consciousness and Cognition 1997; 6: 67-74

96. Toglia MP: Repressed Memories: The Way We Were? Consciousness and Cognition 1995; 4: 111-115 97. Uddin LQ, Rayman J, Zaidel E: Split-brain reveals separate but equal self-recognition in the two cerebral hemispheres. Consciousness and Cognition 2005; 14 : 633-640

98. Vecera SP, Gilds KS: What Is It Like to Be a Patient with Apperceptive Agnosia? Consciousness and Cognition 1997; 6: 237-266

99. Veselis RA: Anesthesia--A Descent or a Jump into the Depths? Consciousness and Cognition 2001; 10: 230-235

100. Ward J, Li R, Salih S, Sagiv N: Varieties of grapheme-colour synaesthesia: A new theory of phenomenological and behavioural differences. Consciousness and Cognition 2007; 16: 913-931

101. Weddell RA: Sequential resolution of fragmented visual percepts: Experimental investigation of a subject's perceptual experience after a right medial temporal stroke. Consciousness and Cognition 2007; 16: $551-576$

102. Weiskrantz L: Pupillary Responses With and Without Awareness in Blindsight. Consciousness and Cognition 1998; 7: 324-326

103. Weiskrantz L: Prime-sight and blindsight. Consciousness and Cognition 2002; 11: 568-581

104. Whitfield CL: The Forgotten Difference: Ordinary Memory versus Traumatic Memory. Consciousness and Cognition 1995; 4: 88-94

105. Young G: Capgras delusion: An interactionist model. Consciousness and Cognition 2008; 17: 863-876 106. Zaragoza MS, Mitchell KJ: Empirical Psychology and the Repressed Memory Debate: Current Status and Future Directions. Consciousness and Cognition 1995; 4: $116-119$ 


\section{Journal of Consciousness Studies}

107. Alkire MT, Haier RJ, Fallon JH, Barker SJ: PET imaging of conscious and unconscious verbal memory. Journal of consciousness studies 1996; 3: 448-462

108. Baron-Cohen S, Bor D, Billington J, Asher J, Wheelwright S, Ashwin C: Savant memory in a man with colour form-number synaesthesia and asperger. Journal of consciousness studies 2007; 14: 237-251 109. Barrantes-Vidal N: Creativity \& madness revisited from current psychological perspectives. Journal of consciousness studies 2004; 11 : 58-78

110. Campbell A: Cartesian dualism and the concept of medical placebos. Journal of consciousness studies 1994; 1: 230-233

111. Cytowic R: The clinician's paradox: Believing those you must not trust. Journal of consciousness studies 2003; 10: 157-166

112. Freeman WJ: Happiness doesn't come in bottles. Neuroscientists learn that joy comes through dancing, not drugs. Journal of consciousness studies 1997; 4: 6770

113. Frith CD, Gallagher S: Models of the pathological mind. Journal of consciousness studies 2002; 9: 57-80

114. Grace V: Embodiment and meaning: Understanding chronic pelvic pain. Journal of consciousness studies 2003; 10: 41-60

115. Gray J, Chopping S, Nunn J, Parslow D, Gregory L, Williams S, Brammer MJ, Baron-Cohen S: Implications of synaesthesia for functionalism: theory and experiments. Journal of consciousness studies 2002; 9: $5-31$

116. Gray R: What synaesthesia really tells us about functionalism. Journal of consciousness studies 2004; 11: 64-69

117. Hill E, Sally D, Frith U: Does mentalising ability influence cooperative decision-making in a social dilemma? Introspective evidence from a study of adults with autism spectrum disorder. Journal of consciousness studies 2004; 11: 144-161

118. Holt J: Blindsight in debates about qualia. Journal of consciousness studies 1999; 6: 54-71

119. Hubbard E, Ramachandran VS: The phenomenology of synaesthesia. Journal of consciousness studies 2003; 10: 49-57

120. Humphrey N: Cave art, autism, and the evolution of the human mind. Journal of consciousness studies 1999; 6: 116-143

121. Hunt H: Synaesthesia, metaphor and consciousness: A cognitive-developmental perspective. Journal of consciousness studies 2005; 12: 26-45

122. Ingvar DH: On volition: a neurophysiologically oriented essay. Journal of consciousness studies 1999; 6: $1-10$

123. Jones RA, Pickles: The person still comes first: The continuing musical self in dementia. Journal of consciousness studies 2006; 13: 73-93
124. Kentridge R, Heywood C: The status of blindsight: near-threshold vision, islands of cortex and the Riddoch phenomenon. Journal of consciousness studies 1999; 6: 3-11

125. Marzi C: Why is blindsight blind? Journal of consciousness studies 1999; 6: 12-18

126. McGeer V: Psycho-practice, psycho-theory and the contrastive case of autism. How practices of mind become second-nature. Journal of consciousness studies 2001; 8: 109-132

127. Meijsing M: Self-consciousness and the body. Journal of consciousness studies 2000; 7: 34-52

128. Merikle PM, Daneman M: Psychological investigations of unconscious perception. Journal of consciousness studies 1998; 5: 5-18

129. Morland A: Conscious and veridical motion perception in a human hemianope. Journal of consciousness studies 1999; 6: 43-53

130. Naudin J, Gros-Azorin C, Mishara A, Wiggins O, Schwartz M, Azorin J: The use of the Husserlian reduction as a method of investigation in psychiatry. Journal of consciousness studies 1999; 6: 155-171

131. Newman J: Putting the puzzle together. Part I: Towards a general theory of the neural correlates of consciousness. Journal of consciousness studies 1997; 4: 47-66

132. Nunez P, Nunez R: Hearts don't love and brains don't pump: Neocortical dynamic correlates of conscious experience. Journal of consciousness studies 2007; 14: 20-34

133. Parnas J: Belief and pathology of self-awareness a phenomenological contribution to the classification of delusions. Journal of consciousness studies 2004; 11 : 148-161

134. Petty PG: Consciousness: a neurosurgical perspective. Journal of consciousness studies 1998; 5: 8696

135. Radden J: Pathologically divided minds, synchronic unity and models of self. Journal of consciousness studies 1998; 5: 658-672

136. Ramachandran VS: Phantom penises in transsexuals. Journal of consciousness studies 2008; 15: 5-16 137. Ramachandran VS, Hirstein W: Three laws of qualia: what neurology tells us about the biological functions of consciousness. Journal of consciousness studies 1997; 4: 429-457

138. Ramachandran VS, Hubbard EM: Synaesthesia -- a window into perception, thought and language. Journal of consciousness studies 2001; 8: 3-34

139. Sass LA: Schizophrenia, self-consciousness, and the modern mind. Journal of consciousness studies 1998; 5: 543-565 
140. Sass LA: Affectivity in schizophrenia a phenomenological view. Journal of consciousness studies 2004; 11: 127-147

141. Schwartz JM: A role for volition and attention in the generation of new brain circuitry. toward a neurobiology of mental force. Journal of consciousness studies 1999; 6: 115-42

142. Snyder D, Fast K, Bartoshuk: Valid comparisons of suprathreshold sensations. Journal of consciousness studies 2004; 11: 96-112

143. Spence SA, Frith CD: Towards a functional anatomy of volition. Journal of consciousness studies 1999; 6: 11-29

144. Sullivan M: Does psychiatry need the Husserlian detour. Journal of consciousness studies 1999; 6: 296299

145. Toombs SK: The role of empathy in clinical practice. Journal of consciousness studies 2001; 8: 247258

146. Varela FJ: Intimate distances. Fragments for a phenomenology of organ transplantation. Journal of consciousness studies 2001; 8: 259-271

147. Walsh R: Can synaesthesia be cultivated?: Indications from surveys of mediators. Journal of consciousness studies 2005; 12: 5-17

148. Watt D: Consciousness, emotional self-regulation and the brain: review article. Journal of consciousness studies 2004; 11: 77-82

149. Zahavi D, Parnas J: Conceptual problems in infantile autism research: Why cognitive science needs phenomenology. Journal of consciousness studies 2003; 10: $53-71$

\section{REFERENCES}

Alkire, M., Hudetz, A., Tononi, G. (2008). Consciousness and anesthesia. Science, 322(5903): 87680 